other doctor (who might be physician to some other dispensary) to have the patient as a private case.

I am willing to abide by any reasonable rule of a dispensary as to the treatment of the poor, but will brook no dictation from any such organization as to whom I shall treat among the well-to.do.

Dr. Bishop, the defendant in the trial between the two homeopathic physicians, sent out a card to the physicians of the city, asking the opinion of the profession in regard to the dispensary abuse. He claims to have over one hundred answers, in which they all denounce the abuse, and agree that dispensaries are solely for the poor, with the privilege of using the patient for teaching purposes.

Respectfully,

WM. E. WIRT, M.D.

\section{Priority in Craniotomy and Microcephalus.}

Graxd Rapins, Micir., Nov. $\tilde{5}, 1894$.

To the Editor:-I desire to state through the JourvaL, that craniotomy for microcephalus is as distinctly American as ovariotomy and several other operations instituted in this country for the benefit of humanity. I take issue with Prof. Carl Beck in his paper published in the Joursal October $2 \overline{7}$, and November 3 , on two points: 1 , in his statement that Cannelongue of Paris, is the pioneer, if I understand the meaning of this word aright to be the man who moves in first. This point, however, does not afflict me since in point of time the date of my operation obliged him to place me first upon the list of operators. I reported two cases in the same paper dated 1878 , which was widely circulated in several countries and severely commented upon by both the medical and secular press. I have operated altogether five times for mental defects, with no deaths. A perusal of my paper will, I think, convince any one that I took care to make a careful diagnosis and that $I$ was at the time conscious of the causes which produce mental imbecility, that my deductions were rational, and that $I$ gave these cases the same careful attention that I give to any case in general practice, for which reason I demur against being set before the profession as an experimenter and human vivisectionist.

Between the years $1876-78$, I read several papers upon affections of the brain before the Montreal Academy of Medicine, which were warmly discussed by such men as Dr. R. P. Howard, Dean of the Medical Faculty of McGill College; Dr. Henry Howard, Superintendent of the Long Point Asylum; Dr: Wm. Osler, of Johns Hopkins, Baltimore; Drs. Hingston, Bass, Boddick, Fenwick, and Dr. Casey Wood, now of Chicago; all eminent men in the profession and severe critics, in the presence of whom it is not reasonable to suppose that $I$ would present a radical departure in any department of medicine, as surgery unsupported by an adequate rationale.

Furthermore, I lay claim to the originality of the introduction of veratrum virid and morphia in the treatment of convulsions and puerperal eclampsia, and of pointing out that these symptoms are caused by arterial spasm and anemia of the nerve centers. I tapped the ventricles of the brain at this time, and discovered that sometimes there was no fluid in cases in which I had expected to find an effusion, which led me to the discovery of a distinction between the coma of compression and the coma of irritation, which was published and, as far as I know, has not been noticed by the profession, though the importance of this distinction ought not to allow it to fall into neglect since the latter class of cases are amenable to treatment successfully by medicine, while the former are, for the most part, hopeless, unless we may expect something by surgical interference.

Yours very respectfully

William Fuller, M.D.
Doctor Diet, Doctor Quiet and Doctor Merryman.

Chicago, Nov. 2, 1894.

To the Editor:-One of the evening papers of this city, in quoting the well-known sentence at the head of this letter, attributes the saying to Jonathan Swift. Will you kindly state if this is correct, and oblige, yours very truly,

ANSwer:-The original is as follows:

INQUIRER.

"Si tibi deficiant medici, medici tibi fiant,

Hiec tria: Mens hilaris. requies, moderata dicta."

This was in the famous "Flos Medicine" or Regimen Sanitatis Salerni, composed in the year 1099 by Johannes de Mediolanus (John of Milan) with the concurrence of the other professors of the celebrated School of Salernum. This book was first translated in English by Paynell in 1579, and later by Dr. Philemon Holland in 1634. Holland's translation of the sentence reads:

"When Physic needs, let these thy doctors bee,

Good dyet, quiet thoughts and heart mirthfull free."

"Mirth," says Burton, 1621 (Anatomy of Melancholy) "is one of the three Salernitan doctors, Dr. Merryman, Dr. Diet, Dr. Quiet, which cure all diseases."

Dean Swift was born in 1667 and died in 1745 , and if he ever used the expression, was too profound a scholar not to have used it as a quotation.

\section{A Good Word for the Eucalyptus.} Chicago, Nov. 5, 1894.

To the Editor:-There may be some foundation for the popular belief that the cultivation of the eucalyptus tree has a salutary influence in antidoting the poison of malaria, though in your editorial in the issue of the Journal of October 27, you discredit it. Our knowledge of the origin and nature of malaria is very vague. I think, however, that rapidly growing vegetation in some way modifies the effects of the poison and renders it less harmful to the human system. I say the human system, for malaria is not observed to have any injurious effect on animals. Perhaps it is assimilated by vegetables in their growth and incorporated into their organized substance. It is likely that all growing vegetation has the same effect.

I lived for a time on the Sangamon "bottoms," when that part of Illinois was newly settled. This was a plain about two miles wide and extending twenty miles from the mouth of the river toward its source. Its elevation was not enough to prevent portions of it from being overflowed when the river was high. It had an alluvial soil of unsurpassed fertility and consequently it produced an enormous vegetable growth. This was then among the most malarious districts in the United States. Agues and other malarial fevers were annually endemic here, from September until the following April. They would then cease until autumn came again. They were not developed when vegetation was in active growth but would return when this process was at rest, yet before the mature vegetation of summer had begun to decay.

Many cases of ill health having an obscure origin and unknown pathology are attributed to malaria, but typical intermittent malarial disease is now but little known in Illinois. I do not think I have seen six cases of shaking ague in Chicago in a quarter of a century. I could find as many in one family at one time on the Sangamon "bottoms" fift years ago. I am told by physicians practicing in that vicinity that it is not prevalent there now. The amount of vegetable product in Illinois has increased many-fold since its soil has been brought under cultivation. The native grasses would not produce more than one ton of hay to the acre. The cultivation of grasses and cereals has greatly increased this amount, and this may be the reason that malarial diseases are no longer common in Illinois. If this theory is true, the eucalyptus, being a tree of phenomenally rapid growth, should have some protective infuence against this class of diseases.

34 Throop Street. 